\title{
Prevalência de cefaleia em pessoas com diagnóstico de disfunção temporomandibular
}

\author{
Beatriz Paiola Albrecht ${ }^{(D)}$, Alcântara Ramos de Assis César (iD) \\ Universidade Federal do Paraná, Curitiba, Paraná, Brasil.
}

\begin{abstract}
Introdução
A Disfunção Temporomandibular (DTM) é uma anormalidade que engloba as articulações temporomandibulares e os músculos da mastigação, tendo como provável sintoma predominante a cefaleia. Sendo ela uma dor em pressão com acometimento da face e das têmporas.
\end{abstract}

\section{Objetivos}

Demonstrar a prevalência de DTM na população da Vigésima Regional de Saúde do Paraná; traçar um perfil dos pacientes com diagnóstico de DTM; identificar a prevalência de cefaleia em portadores de DTM e correlacionar as duas patologias nos pacientes estudados.

\section{Material e Métodos}

Estudo quantitativo e retrospectivo (2019 a 2020), com cálculo da razão de prevalência realizado na população atendida pelo CISCOPAR (neurologia, bucomaxilofacial e protesista), com verificação de prontuários de 3.175 pacientes. Utilizando como base metodológica o trabalho de Pereira et al (2018).

\section{Resultados}

296 pacientes apresentavam cefaleia descrita, sendo a maioria mulheres (73\%) com idade entre 18 e 50 anos (57\%). A prevalência de DTM diagnosticada é de 1,39\% (44 pacientes) e a razão de prevalência (RP) de DTM associada à cefaleia é de 0,17 (IC 95\% 0,05-0,52; p<0,001). No entanto, sinais e sintomas diretamente relacionados à DTM (dor durante a fala/mastigação, sono ruim, ansiedade, zumbido e sonolência excessiva diurna) foram relatados por 71 pacientes. Portanto, a prevalência de DTM obtida é inferior à média populacional de sintomas associados a DTM de 6,0\% ( $<<0,001)$, assim como RP de DTM relacionada à cefaleia, também é estatisticamente inferior à média populacional (Sarnat \& Laskin 1992), o que indica um possível subdiagnóstico dessa patologia. Visto que a presença de cefaleia é significativa na população atendida e poucos casos tiveram a DTM como hipótese diagnóstica.

\section{Conclusão}

É fundamental o reconhecimento dos sinais e sintomas relacionados à DTM, garantindo um tratamento precoce e adequado para evitar os impactos negativos que essa disfunção pode causar na vida dos pacientes.

Palavras chave: Articulação Temporomandibular, Cefaleia, Subdiagnóstico, Disfunção Temporomandibular 